\section{PHOTOGRAPHY AS A SCIENTIFIC INSTRUMENT}

$\mathrm{T}$ HE first meeting of the newly founded Association for Scientific Photography was held at the Royal Institution on June 5. Prof. J. Yule Bogue, in his opening address, on applied photography, said that with the rapid growth of science and technology in the last decade, workers, whether they be in the industrial or purely scientific fields, have found it increasingly difficult to keep in touch with the recent advances in fields other than their own. Any particular branch of industry or science is largely dependent for its own advancement upon the progress made in other branches. In order that the maximum benefits may accrue, it is essential that knowledge of these advancements be disseminated as widely as possible. The Association for Scientific Photography has been formed to do this in respect of the development and application of photography as a scientific instrument in industry, technology, medicine and science. The association will assist its members in the solution of problems of development, production and research, by the application of photographic methods. It caters primarily for those who apply or could apply photographic techniques to their work, as opposed to photographers who are interested in the application of their work to scientific problems. It is essential, therefore, that there shall be close co-operation with those concerned with the technical developments of photographic science, so that the results of their work shall be readily available for application by those working in science and industry.

The applications of photography to industrial work, development, and research are enormous. Some indications of this are given in the questionnaire which members are required to fill in, stating whether they are interested in the application of photography to pure research, for example, tracks of atomic particles ; or industrial research, for example, the study of vibration in air-screw blades; or production, for example, the radiography of castings ; or recording for instructional purposes, for example, documentary kinematography.

He thinks that one important result of the meetings of the Association would be the bringing together, through a common interest, of workers from widely different fields of industry and science. This will be to their mutual advantage, for not only will they discuss their photographic problems, but also their particular lines of investigation.

Prof. Bogue then dealt with some specific applications of photography, confining his choice to a few examples which incorporated several photographic techniques and had more than one specialized application. By the Schlieren photographic method, changes in the refractive index of the atmosphere are made visible. The changes may be sudden, such as those produced by the detonation of explosive mixtures, or they may be slow, such as those brought about by changes in temperature. The method has been used successfully in conjunction with the highspeed camera, in studying the properties of aerofoils. The design of radiators, heating elements, and heat-dissipating surfaces, also lends itself to this form of control. With stroboscopic light sources, using gaseous discharge lamps and oscillating circuits, photographs of the distortion of air-screw blades rotating at high speed can be made. The modern gaseous discharge lamp can be made to give an exposure so short as $1 \mu$ sec. $(=0.000001$ sec.), and can be used with either the still or high-speed camera.

Photo-elastic analysis has obvious uses in the study of components of machines and other structures subjected to stresses. This technique has also proved of value in understanding the stresses set up in the brain as a result of head injuries.

Photo-micrography has a wide range of application, from the control of galvanizing and the study of metal structure, to the study of fibres in the textile industry and histological investigations in medicine. 'Time lapse kine-photomicrography, for example, has yielded much information on the development of the mammalian ovum, which could not have been obtained by any other means.

Photography has many applications in medicine. Mass radiography, for example, has been assisted by the development of wide-aperture lenses and special emulsions, thus closely linking radiography and photography. Indirect radiography is not confined to diagnostic work; it has also proved invaluable in the study of normal function. The $16 \mathrm{~mm}$. film has become one of the most useful media for teaching and research purposes in biology and medicine. The study of living things in action lends itself particularly to kinematographic analysis.

A colour film of the contraction of the spleen was then shown to demonstrate the value of split-screen work for teaching purposes.

In her paper on "Indirect Radiography as Applied to Medical Work," Miss K. C. Clark dealt with that branch of radiography in which the image on the fluorescent screen is photographed. A still indirect radiograph is obtained when a single exposure is made on a small film, or a kine-radiograph, recording movement, when a kine-camera is employed.

Indirect radiography has enabled the Ministry of Health to launch a scheme which eventually may lead to every member of the community having his or her lungs examined annually by miniature radiography. This examination is for the purpose of discovering symptomless tuberculosis of the lungs, which may only be apparent on X-ray examination and which may not be discernible by routine medical examination. Such an examination of large numbers at sufficient speed, which was impossible by the direct method, has been solved by the application of miniature radiography.

The first practical application of the method was in Brazil in 1934. It has since been employed for the native miners in South Africa, in the Fighting Services, in Australia and America, and in Germany. It has been left to Great Britain, after employing the method to examine men and women in the Services, to introduce a national scheme, which, beginning with the twenty-five special X-ray units, will eventually and by gradual infiltration service the whole country. New units are being delivered each month and personnel trained in their operation. With one of these units, subjects are being examined at a rate of more than 500 a day. The unit can deal with four persons a minute, and the whole process for each person-undressing, taking information for records and identification purposes, and redressing, takes 1015 minutes. The size of film used for this work is still a matter for discussion; the most widely used in Great Britain is the $35 \mathrm{~mm}$. cine film. The lenses have an aperture ranging from $F / 1$ to $F / 2$. Miss Clark uses the Taylor, Taylor and Hobson $F / 1 \cdot 5$ 
coated lens. In most units a fluorescent gcreen is fitted to the wide end of a light-proof tunnel which has an automatic camera at the smaller end. These specially designed cameras are linked with and operated from the X-ray exposure control. Identification is ensured by illuminating the serial number on the subject's card and photographing it on to the base of the film upon which the radiograph is taken. Since the patient hands his card to the operator, there is no possibility of error. The average exposure time is $0.1 \mathrm{sec}$. or $20 \mathrm{~mA}$.-sec., with a variation of 2 kilovolts for each half inch of chest thickness, with a reduction of time down to $0.05 \mathrm{sec}$. for smaller thicknesses, and an increase in time to 0.2 sec. for outsize subjects.

Special training is needed in the handling of miniature films, as minute defects show up on projection, especially when the viewer sits within 20 in. of the white matt surface screen. These films are viewed at a rate of $200-450$ an hour. A complete radiological interpretation is never given on a miniature film, and a film showing a technical error is never repeated on a miniature. For both reasons, subjects are recalled for full-sized $\mathrm{X}$-ray examination ; about 5 per cent are recalled, but the number found to have tuberculosis does not exceed 1 per cent.

Miss Clark then mentioned points for future discussion, which included various aspects of design of the X-ray equipment, screens, cameras, films and processing. Mention was also made of the 5 in. $X$ 4 in. method used in the United States. This is much slower than the $35 \mathrm{~mm}$. film method, because the individual films have to be handled separately throughout, though there is the advantage of direct viewing without enlargement. The paper concluded with a brief reference to indirect kine-radiography, in which the screen image is photographed by means of a $16 \mathrm{~mm}$. camera fitted with an $F / 0 \cdot 85$ lens. At present, this work is chiefly of academic interest and is used for research purposes.

In his paper on "Some Miscellaneous Applications of Industrial Radiography," Dr. L. Mullins described the diverse applications of radiography for inspection and also its use purely as an investigational tool incidental to the main problem. He mentioned that radiography as an inspection technique is playing an ever-increasing part in the national war effort, not only in the well-known application to the examination of castings and welds for porosity, cracks, slag inclusions and other defects, but also in the inspection of such products as electric cables, plastic assemblies, transformer windings on cardboard formers and wireless valves.

The application of radiography to the examination of wireless valves provided Dr. Mullins' first example of the use of X-rays as an investigational tool, since they may be applied in the study of filament distortion while the valve is working. Radiography has also been used in the determination of the rate of increase in the compressive stress in steel due to nitriding. In this work, reported by Betteridge, a flat steel strip, with its underside protected from nitriding by tin plating, was placed in contact with a steel block in the nitriding furnace. Radiographs made through the walls of the furnace prior to and during nitriding revealed the curvature caused in the steel strip and enabled calculation of the stress at the various stages concerned. Additional radio. graphs made during cooling provided information on the differential expansion of the metal core and the nitride casing.
Further examples of this type concerned the determination of the internal bore of glass tubes, of capillary measurements involving liquids in opaque tubes and of the viscosity of tooth paste, and an investigation of the nature of sodium silicate bonds in corrugated cardboard. This last application provided hitherto unknown information concerning the physical structure of the adhesive joint, the location of the adhesive within, and on, the paper, and the relation of the joint structure to the physical properties of the corrugated board.

As examples of the applications of X-rays in biology, Dr. Mullins cited investigations on the movements of death watch beetle larvæ, and the radiographic method for the vitamin D content of cod liver oil for poultry feeding.

Where rapidly changing phenomena, such as the movement of a piston within an opaque cylinder, have to be examined, kine-radiography has proved of considerable value despite the limitations on its scope, due to the fact that the intensity of the photographic effect on the recording medium is entirely dependent on the output of the X-ray equipment. Two techniques are available: first, the indirect method, in which a kine-camera is used to record the fluorescent screen image; and seondly, the direct method in which the X-ray beam, after passing through the specimen, is recorded directly on kine films. In the latter technique greater taking speeds may be achieved by the use of intensifying screens in contact with the film. The direct method was used by Sack in a study of the metal drop formation in electric welding. Previous photographic studies using slow-motion kine techniques had provided incomplete information owing to the presence of hot gases and vapours in the welding zone and the very bright welding arc; these difficulties had, however, been overcome to some extent by the use of infra-red sensitive materials and suitable filters. X-ray technique not only surmounted these difficulties but also enabled differentiation between the core and coating of coated welding rods. Sack's apparatus was designed to take twenty-five frames every two seconds, and the results obtained provided extensive information on the nature of the drop formation in various circumstances, showing, for example, that, with heavily coated electrodes, the drops form within the coating and fall before their diameter exceeds that of the electrode.

Where the effect being studied takes place in too short a time for kine-radiography to produce useful results, the possibility of high-speed radiography should be considered. Many attempts have been made to produce $\mathrm{X}$-ray tubes capable of generating and withstanding very high instantaneous loads. Steenbeck and also Kingdon and Tanis have described X-ray tubes in which a pool of mercury serves as the target : the disadvantages of this design are that the mercury must be cooled to maintain a low vapour pressure and that the X-ray tube can be used in only one position. Oosterkamp devised an X-ray tube for this purpose in which high instantaneous loads are applied by discharging a condenser across the tube while momentarily increasing the filament current. Recently Slack and Ehrke have described a cold-cathode X-ray tube across which a bank of condensers is discharged by a relay linked with the effect being studied. This tube is capable of providing an electron flow across the tube as great as 2,000 amp. at $100 \mathrm{kV}$. for a millionth of a second. 
With this equipment Slack and Ehrke have already investigated, among other things, the passage of bullets through wood, the movements of the bones in the foot when kicking a ball and the movement of dust in the intake duct of a vacuum cleaner.

In closing, Dr. Mullins said that, as this brief survey would show, the scope of industrial radiography is indeed wide, and he ventured to suggest that, with the active co-operation of radiographers and of the manufacturers of $\mathrm{X}$-ray equipment and $X$-ray films, even wider applications than are considered feasible at present would become evident.

C. D. Reyersbach's demonstration of "Substandard Kine-photo-micrography" was presented by J. Alsop. The purpose of the demonstration was to indicate the application of the kine-camera to photomicrography for determining and recording the movements of small bodies. This was dramatically shown in a colour film of pond life and the growth of crystals. The film was made by the author in collaboration with Alsop, L. Elliott and A. Sabin. The apparatus required is that used for still photomicrography, with the addition of a kine-camera. It is desirable and useful to incorporate an optical arrangement enabling the operator to watch the field of the microscope while the exposures are being made; this was done in the case of the film presented.

The method of dark-ground illumination used was a differential one, the object of this being to increase contrast, while at the same time minimizing glare that is apt to arise with rather transparent objects when ordinary dark-ground illumination is used. This illumination is obtained by mounting behind the condenser of the microscope a central disk of one colour with a disk of another colour around it. The colour of the central disk will then provide the background, while the object will be illuminated by light of the colour of the outer disk. In the case of the shots showing the growth of crystals, a polarizer and analyser were used. The examples shown were all low-power work, but the principles are precisely the same where higher powers are required. The problem of exposure is one which requires careful consideration, and it is found that the exposures required are considerably shorter than anticipated. The exposure of short test strips, together with a complete record for future guidance, is advised.

Mr. H. McGregor Ross, in his paper "The Photography of Photo-elastic Stress Patterns", said that photo-elastic stress analysis offers the engineer a most effective method of solving problems of stress distribution. It is not only frequently simpler and quicker than other methods, but also it may be used

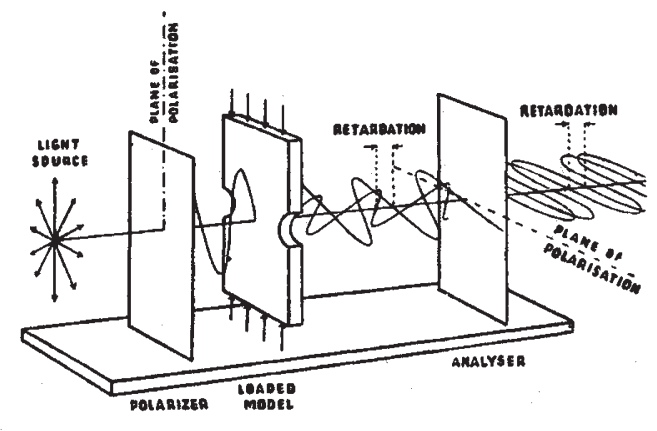

Fig. 1.

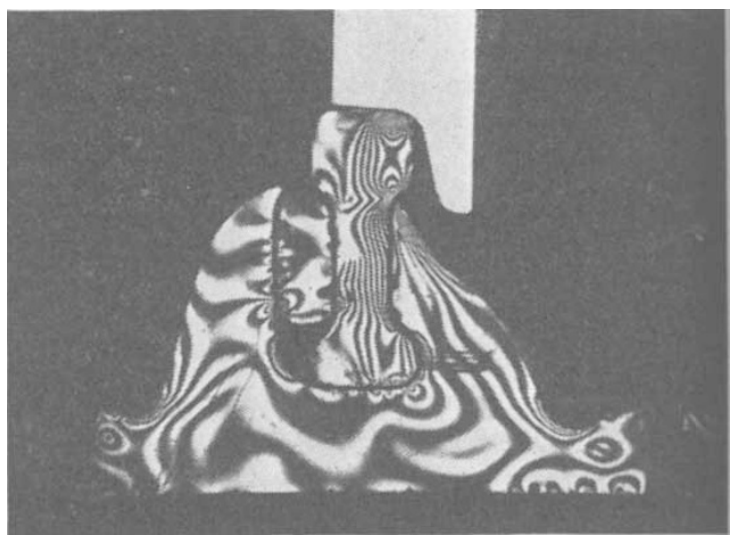

Fig. 2.

to solve problems otherwise insoluble or at least demanding tedious computations.

The majority of stress distribution problems may be simplified by considering the two-dimensional system of stresses in a section of the object under investigation. These stresses may be completely determined by finding the magnitude and direction of the two 'principal stresses', and photo-elastic stress analysis is particularly well suited for obtaining this information.

A transparent scale model is made of the section of the object, using a suitable plastic material. Loads which are proportional to the loads in the real object are then applied to the model, and it is viewed by polarized light in a polariscope. If a monochromatic light source is used, a pattern of light and dark lines will be seen in the model, and it is from these lines that the magnitude of the stresses may be determined. Each line may be considered as a 'contour' of stress, the difference between the two principal stresses being the same at every point along each line; the value of this difference is found by a previous simple test. The stresses in the actual object will be proportional to those found in the model.

The optical theory is shown simply in Fig. 1. Light from the source passes through a polarizer and emerges plane-polarized. The material of which the model is made has the property of becoming birefringent when stressed, so that the polarized light is split into two components on entering the stressed model. The direction of vibration of these components is the same as the directions of the principal stresses. While passing through the model, one component will travel more slowly than the other, so that it will be 'retarded' on emerging from the model. The extent of this retardation is proportional to the magnitude of the difference between the two principal stresses. The two components are combined by being passed through the analyser, and the interference effects caused by the retardation gives rise to the stress pattern observed in the model. If a white light source is used, the resulting stress pattern will consist of coloured lines, the colours being similar to those given by any interference phenomenon. Photographs in natural colours were shown of typical stress patterns.

At all points in the model where the direction of one of the principal stresses coincides with the plane of the incident polarized light, the light passes straight through the model and is cut out by the analyser. This results in a dark line-the isoclinic lineappearing in the model, from which the direction of 
the principal stresses may he found. If it is required to find the magnitude of each principal stress separately, a further technique is required which was not considered in this paper.

In order that these patterns may be photographed successfully, it is necessary to use a suitable polariscope. An instrument which had been found satisfactory was demonstrated, and various points in its design were discussed. With this instrument photographs had been obtained with very short exposures. Consideration was also given to the best photographic materials for this type of work.

A recent development, particularly in Great Britain, has been the combination of photo-elastic stress analysis with the technique of high-speed photography for recording sudden dynamic stresses, carried out at the Research Laboratories of Kodak Ltd. Two methods are available : in the first, a brilliant flash of very short duration is used to record a very rapidly moving phenomenon, and a photograph was shown taken in natural colour with the 'Kodatron' Speedlamp at an exposure of about $1 / 10,000$ sec. In the second method, a cine-film, taken at a very high rate, is then projected at a normal rate so that the action is greatly slowed down. Such a film, believed to be the first of its type taken in natural colour, was shown ; in this, the exposures were taken at the rate of 1,000 per second. It showed the stresses found in the chair holding a railway line to the sleeper, and a 'still' from the film is shown in Fig. 2.

Prof. Bogue said, in closing the meeting, the programme must surely have demonstrated that photography is a scientific instrument capable of many and varied applications.

\section{U.S. NATIONAL ACADEMY OF SCIENCES}

\section{ANNUAL MEETING}

A T. the annual meeting of the U.S. National Academy of Sciences held on April 27, the following officers and new members were elected :

President: Dr. Frank B. Jewett, re-elected for a further term of four years. Home Secretary: Dr. F. E. Wright, refelected for a further term of four years. Members of Council: W. Mansfield Clark, De Lamar professor of physiological chemistry, Johns Hopkins Medical School (re-elected); Walter $\mathbf{R}$. Miles, professor of psychology, Yale University School of Medicine (succeeding Prof. Oswald Veblen).

Foreign Associates : Alfonso Caso, Instituto Nacional de Antropologia e Historia, Mexico City; Sir Harold Spencer Jones, Astronomer Royal, Royal Observatory, Greenwich; Dr. R. V. Southwell, rector of the Imperial College of Science and Technology, London; Prof. C. E. Spearman, emeritus professor of psychology in the University of London; Sir D'Arcy Thompson, professor of natural history in the University of St. Andrews; Dr. H. J. van der Bijl, chancellor of the University of Pretoria.

New Members of the Academy: L. H. Adams, Geophysical Laboratory, Carnegie Institution of Washington; Dr. A. Adrian Albert, assistant professor of mathematics, University of Chicago ; Prof. J. W. Beams, professor of physics, University of Virginia; Prof. A. F. Buddington, professor of geology, Princeton University; Dr. Leonard Carmichael, president of Tufts College, Medford, Mass. achusetts; Prof. W. H. Chandler, professor of pomology, University of California, Los Angeles; Prof. E. J. Cohn, professor of biochemistry, Harvard Medical School; Prof. J. N. Couch, professor of botany, University of North Carolina; Prof. Th. Dobzhansky, Columbia University ; Prof. Løe A. DuBridge, professor and chairman of the Department of Physics, University of Rochester ; Dr. L. C. Dunn, professor of zoology, Columbia University; Prof. Wallace O. Fenn, professor of physiology, University of Rochester ; Dr. Paul D. Foote, director of research and executive vice-president, Gulf Research and Development Company, Pittsburgh, Pa.; Prof. L. P. Hammett, professor of chemistry, Columbia University ; Prof. William V. Houston, professor of physics, California Institute of Technology, Pasadena, California ; Prof. Walter P. Kelley, professor of agri- cultural chemistry, Citrus Experiment Station, Riverside, California; Dr. Warfield T. Longcope, professor of medicine, Johns Hopkins University; Dr. E. K. Marshall, jun., professor of pharmacology and experimental therapeutics, Johns Hopkins Medical School ; Dr. L. Michaelis, Rockefeller Institute for Medical Research, New York; Dr. W. Albert Noyes, jun., professor of physical chemistry, University of Rochester ; Prof. O. H. Robertson, professor and head of the Department of Medicine, University of Chicago ; C. G. Rossby, University of Chicago ; Prof. Calvin P. Stone, professor of psychology, Stanford University; Dr. C. V. Taylor, professor of zoology, Stanford University; Dr. H. B. Vickery, in charge of Biochemical Laboratory, Connecticut Agricultural Experiment Station, New Haven, Connecticut; Dr. V. K. Zworykin, director of the Electronic Research Laboratory, RCA Manufacturing Company, Camden, N.J.

\section{Presentation of Medals}

The following five gold medals were presented :

Henry Draper Medal for 1942, to Ira Sprague Bowen, of the California Institute of Technology, Pasadena, California, in recognition of his contributions to astronomical physics; more especially his researches on the spectra and chemical composition of the gaseous nebulæ. Best known and one of Dr. Bowen's most brilliant accomplishments was his discovery of the nature of 'nebulium' lines, a most difficult problem solved by him after the ablest spectroscopists had struggled with it for three quarters of a century and had failed. This discovery and the results of his subsequent researches yielding the identification of numerous other forbidden lines in nebular and stellar spectra constitute some of the most important advances in astrophysics within recent years.

The Draper Medal is provided by the income from a trust fund given to the Academy in 1883 by Mrs. Henry Draper in memory of her husband, a former member of the Academy. It is awarded for investigations in astronomical physics. The present award is the twenty-sixth.

Agassiz Medal for 1942, with accompanying 